RESEARCH REPORT

\title{
Midlife suicide risk, partner's psychiatric illness, spouse and child bereavement by suicide or other modes of death: a gender specific study
}

\section{Esben Agerbo}

Study objective: To describe gender specific suicide rates associated with partner's psychiatric disorder, loss of a spouse, or child by suicide or other causes, being a parent, and marital status.

Design: Nested case-control study. Information on causes of death, psychiatric admission, marital status, children, and socioeconomic factors was obtained from routine registers.

Setting: Denmark.

Participants: 9011 people aged 25-60 years who committed suicide; 180220 age-gender matched controls; 111172 marital partners; 174672 children.

Main results: The suicide risk in women whose partner had been first admitted with a psychiatric disorder after 31 December two years earlier was 6.9 (95\% Cl 3.6 to 13.0), whereas their male counterpart experienced a risk of 3.9 (2.7 to 5.6); $p$ value gender difference $=0.39$. Men who had lost their partner by suicide or other causes of death experienced a suicide risk of 46.2 (18.3 to 116.4) and 10.1 (6.5 to 15.8), respectively; the analogous risk among women were about one third: 15.8 (6.6 to 37.4) and 3.3 (1.5 to 7.2), respectively. Child bereavement by suicide or other causes imposed an approximate twofold risk

Correspondence to: Dr E Agerbo, National Centre for Register-based Research, University of Aarhus, DK-8000 Aarhus

C, Denmark; ea@ncrr.dk

Accepted for publication 30 July 2004 increase in their parents, whereas being a parent was protective in women. Except for widows (1.6, 1.2 to 2.0) and widowers (3.0, 2.3 to 3.9) the suicide risk associated with being separated (2.0, 1.8 to 2.3), divorced $(1.8,1.7$ to 2.0$)$, never married $(1.4,1.3$ to 1.6$)$, cohabitant $(1.2,1.1$ to 1.3$)$ was virtually the same in the two sexes.

Conclusions: The suicide risk is associated with partner psychiatric illness. Conjugal bereavement is particularly indicative of suicide in men, and spousal suicide is particularly indicative of suicide. Child bereavement is associated with parental suicide, while being a parent is protective against suicide in women.

$\mathrm{T}$ he importance of familial aggregation of suicides and psychiatric disorders in understanding suicidal behaviour and preventing suicide is well recognised. ${ }^{1-3}$ Some explanations have been that genetic factors play a part in mediating the transmission of familial suicides and psychiatric illness, ${ }^{4-6}$ or that the familial clustering could be caused by the effect of shared environmental factors. ${ }^{7}$ Although these explanations are inseparable in most studies, using information on twins, ${ }^{6}$ who share genes but also most often upbringing, and adoptees, ${ }^{5}$ who only inherit their biological parents genes, studies have tried to tease out the contribution of the genetic components. However, specific genes associated with suicide and psychopathologies in almost all psychiatric conditions are yet to be identified. ${ }^{8-12}$ A previous study ${ }^{13}$ by the author has suggested that the suicide or mental illness of a spouse imposes an environmental rather than a genetic influence. However, such a link might arise as a spurious association through assortative mating. ${ }^{13}{ }^{14}$

Nevertheless, experiencing a spouse or a child dying, or a spouse suffering from a psychiatric disorder are stressful life events. Bereavement studies have confirmed that the mortality is increased in surviving spouses ${ }^{15}$ and parents, ${ }^{16}$ and particularly in widowers, ${ }^{17}{ }^{18}$ and studies have suggested that spouses are affected by their partner's mental health. ${ }^{19}$ Suicidal thoughts are not uncommon in the bereaved, ${ }^{20}$ and a previous study suggests that spousal bereavement through suicide increases the suicide risk more than bereavement by other modes of death. ${ }^{13}$ Losing a child is associated with the risk of suicide, ${ }^{16}$ whereas being a parent is protective against suicide. ${ }^{16}$
Few studies have examined gender differences for these risk factors, while adjusting for presumably important confounders and risk factors, such as own psychiatric admission, ${ }^{21}$ marital status, ${ }^{22}$ and labour market status, ${ }^{23}{ }^{24}$ which is therefore the aim of this study.

\section{METHODS}

Data were obtained by linking Danish population based registers using the unique personal identification number, which is assigned to all persons living in Denmark and used across all registration systems. ${ }^{25}$

The Danish Civil Registration System ${ }^{25}$ was used to identify children. After April 1968, linking information between parents and children relies basically on birth registrations, and before 1968, parents were identified as the adults sharing the same address as the child. A link to a father would be missing if a woman, who was living alone, did not identify the father, which would be uncommon because of the father's mandatory alimony pay to child support.

The Danish Medical Register on Vital Statistics contains dates and causes of all deaths in Denmark recorded from the cause of death certificates. ${ }^{26}$ Suicide was defined as ICD $8^{27}$ codes E950-959 and ICD10 ${ }^{28}$ codes X60-X84. ICD9 was never used in Denmark.

The Danish Psychiatric Central Register includes all admission and discharge dates and diagnoses according to the World Health Organisation ICD8 and ICD10 classification of all psychiatric inpatient facilities in Denmark since 1969. ${ }^{29}$ There are no private psychiatric hospitals in Denmark, and all treatment is free of charge. 
The Integrated Database for Longitudinal Labour Market Research $^{30}$ covers the entire population and contains yearly information from 1980 and onwards with information from administrative registers. Furthermore, the register contains identification numbers of spouses and cohabitees recorded on 31 December. A cohabitee is a non-first degree relative of the opposite sex with an age difference $<15$ years who is sharing a residence with only two adults.

All subjects, aged 25 to 60 years, who had committed suicide during the period 1982 to 1997, were identified from the Danish Medical Register on Vital Statistics. Using a nested case-control design, each person committing suicide was matched to a random subsample of exactly 20 persons of the same sex, who were born the same year and who were alive at the particular matching date and age (in days) - that is, the gender-birth year stratified controls were at risk at the same age and date. ${ }^{31}$ To make the selection feasible and to minimise the computational burden, a random 5\% sample was selected from the entire population within which controls were randomly selected. Cases and controls were only included if they had been living in the country during the two preceding years. All spouses and cohabitees living with the subjects on 31 December two years before, and children were then identified.

The variables derived from the Danish Psychiatric Central Register were duration of current discharge period and diagnosis at latest discharge. Information on the partner and children, before the particular matching date, was added from the Danish Medical Register on Vital Statistics. Figure 1 describes the study design. Note that a spouse can only die in the period between 31 December two years earlier and the matching date.

Demographic and socioeconomic factors included were variables describing marital status on 31 December two years earlier (cohabitating or married and living with the spouse, living alone and being widowed, divorced, married but separated, or never married), job status during the previous year (fully employed or self employed, unemployed for $1 \%-$ $20 \%, 21 \%-80 \%$, and $81 \%-100 \%$ of the year, recipients of other social benefits including disability pensioners, housewives, and a few students), educational achievement (university, bachelor or other of similar duration, vocational training, high school, primary school, and unknown), gross income the previous year (age-gender-year specific quartiles), number of children born before the matching date. Through the Danish Civil Registration System, ${ }^{25}$ historical information on widowhood and whether never married stems back to 1924,

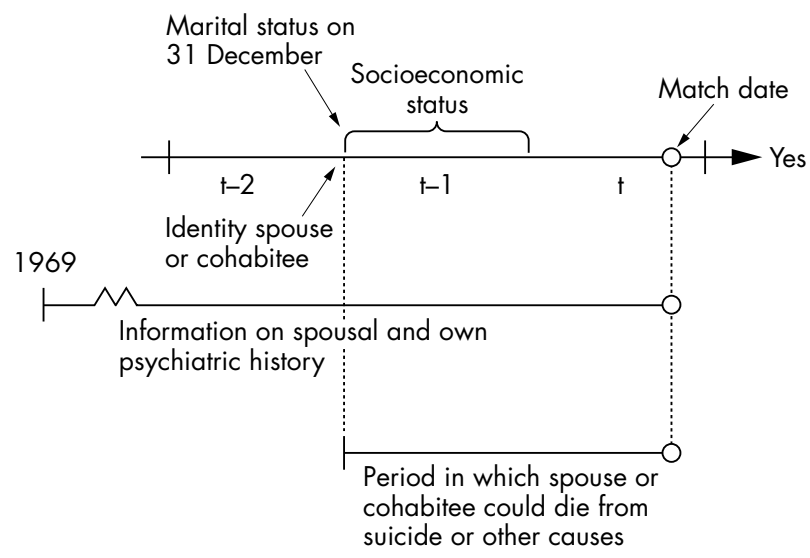

Figure 1 Design and definition of primary explanatory information included in the analysis of suicide risk in the years $(=t)$ from 1982 to 1997. Information on children is available if they are born after 1968 or living with the parent after April 1968. when local municipal registers were created..$^{32}$ It is mandatory to report a change of address within five weekdays.

Data were analysed by conditional logistic regression, with each case forming a separate stratum, using the PhReg procedures in SAS (version 8.1), and relative risks, Wald statistics (W), 95\% confidence bands, and associated $\mathrm{p}$ values were computed. ${ }^{31}$ Age interactions were tested by including age in years as a continuous covariate among the exposed and zero otherwise. The first model (model 1$)$, the second model (model 2), and the third model (model 3) included the risk factors separately, simultaneously, and simultaneously by gender in a multivariable model.

\section{RESULTS}

In total, 9011 (2867 female) cases and 180220 controls were identified. The distribution of cases and controls over the risk factors are shown in the first column of the tables.

The risk of suicide was increased if a spouse or cohabitee had been admitted with a psychiatric disorder (table 1: age and sex adjusted risk rates; model 1), and particularly, if the first admission had been within the period from 31 December two years earlier and until the matching date, which is a period of less than two years. The suicide risk was less pronounced if the partner had been admitted before 31 December two years earlier.

The risk of suicide was increased among people whose spouse or cohabitee had died. The death of a spouse or a cohabitee by suicide was more indicative of suicide, whereas there were no differences between spouses and cohabitees. People who were married and living with their spouse had a lower suicide rate, while the suicide rate was increased among people who were separated, and slightly increased in cohabiting couples.

When all factors, including the persons' own psychiatric admission, death of children, and socioeconomic status, were considered (table 1: column 4; model 2), the suicide risk remained increased among people whose spouse or cohabitee had been admitted with a psychiatric disorder. This increase was particularly pronounced if the spouse or the cohabitee had been first admitted during the period since 31 December two years before. The concordance of psychiatric admission in both partners (risk ratio 1.02; 95\% confidence interval, 0.78 to 1.34 , no cases/controls $=235 / 363$ ) and the partner's psychiatric diagnosis did not affect the suicide rate $(\mathrm{W}=2.98, \mathrm{df}=4, \mathrm{p}=0.56)$. The death of a spouse or cohabitee remained strongly related to suicide in the surviving partner. Suicide bereavement was more indicative of suicide in spouses $(\mathrm{W}=6.83, \mathrm{df}=1, \mathrm{p}=0.009)$ and cohabitees ( $\mathrm{W}=4.90, \mathrm{df}=1, \mathrm{p}=0.03$ ) but not statistically different for spouses and cohabitees. Compared with the married, people who were cohabiting or living alone were at a higher risk of suicide. The effect decreased slightly with age in the divorced and the never married persons.

Table 2 shows the results concerning the effect of the confounding risk factors (model 1 and 2). There were higher rates of suicide in psychiatric patients-especially shortly after hospital discharge (model 2). Among people previously admitted to a psychiatric hospital, patients admitted with depression experienced a higher suicide risk, whereas the rate associated with schizophrenia and alcohol misuse was smaller than the rate associated with other psychiatric disorders. Compared with the general population, the risk ratio associated with a specific diagnosis must be multiplied by the relevant risk ratio associated with duration since last discharge. The unadjusted suicide risk seemed more closely related to suicide than other modes of death of a child. This difference disappeared after adjusting for parental psychiatric admission (data not shown). Being a parent was protective against suicide, especially if to more than one child. The 
Table 1 Suicide in relation to spousal or cohabitant's psychiatric admission, suicide, or other mode of death for the 9011 people who committed suicide and 180220 controls

\begin{tabular}{|c|c|c|c|}
\hline Risk factor and category & Number of cases/controls & $\begin{array}{l}\text { Adjusted for age and sex* } \\
\text { (model 1) }\end{array}$ & $\begin{array}{l}\text { Incidence rate ratios adjusted for } \\
\text { age, sex, and the factors in } \\
\text { table } 1 \text { and table } 2 \text { (model 2) }\end{array}$ \\
\hline \multicolumn{4}{|l|}{ Partner's psychiatric admission history } \\
\hline Spouse 1.admission after 31 Dec two years before & $57 / 256$ & 7.34 (5.50 to 9.81$)$ & 4.97 (3.46 to 7.14$)$ \\
\hline Spouse 1.admission before 31 Dec two years before & $190 / 2821$ & 2.21 (1.90 to 2.57 ) & $1.22(1.01$ to 1.46$)$ \\
\hline Spouse never admitted & $3167 / 104681$ & 1 & \\
\hline Cohabitee 1.admission after 31 Dec two years before & $16 / 83$ & $4.72(2.75$ to 8.10$)$ & 3.01 (1.49 to 6.08 ) \\
\hline Cohabitee 1.admission before 31 Dec two years before & $119 / 1006$ & $2.77(2.27$ to 3.40$)$ & 1.36 (1.06 to 1.74 ) \\
\hline Cohabitee never admitted & $927 / 23363$ & 1 & \\
\hline \multicolumn{4}{|l|}{ Partner's suicide and death since 31 Dec two years before } \\
\hline Spouse suicide & $21 / 29$ & 23.59 (13.43 to 41.45$)$ & 22.13 (11.30 to 43.35$)$ \\
\hline Spouse death by other cause & $38 / 132$ & $9.25(6.44$ to 13.30$)$ & $7.67(4.98$ to 11.81$)$ \\
\hline Spouse alive at the matching date & $3355 / 107597$ & 1 & \\
\hline Cohabitee death by suicide & $7 / 5$ & 36.21 (11.40 to 115.00$)$ & $31.16(8.91$ to 108.89$)$ \\
\hline Cohabitee death by other cause & $16 / 34$ & $10.47(5.75$ to 19.09$)$ & $6.03(2.79$ to 13.01$)$ \\
\hline Cohabitee alive at the matching date & $1039 / 24413$ & 1 & 1 \\
\hline \multicolumn{4}{|l|}{ Marital status on 31 Dec two years earlier } \\
\hline Widow/widower & $208 / 2367$ & $2.67(2.29$ to 3.10$)$ & $2.14(1.79$ to 2.56$)$ \\
\hline Separated & $486 / 4437$ & 3.67 (3.44 to 3.93 ) & 2.01 (1.78 to 2.27 ) \\
\hline Divorced & $1315 / 11222$ & 3.51 (3.17 to 3.88$)$ & $1.79(1.65$ to 1.95$)$ \\
\hline Never married & $2526 / 29984$ & 3.06 (2.88 to 3.24$)$ & $1.43(1.32$ to 1.56$)$ \\
\hline Cohabitant and living with partner & $1062 / 24452$ & $1.54(1.43$ to 1.66$)$ & 1.15 (1.05 to 1.25 ) \\
\hline Married and living with spouse & $3414 / 107758$ & 1 & 1 \\
\hline
\end{tabular}

Table 2 Suicide in relation to psychiatric admission; suicide and death among children and number of children, income, labour market affiliation, and educational attainment

\begin{tabular}{|c|c|c|c|}
\hline Risk factor and category & $\begin{array}{l}\text { Number of cases/ } \\
\text { controls }\end{array}$ & $\begin{array}{l}\text { Adjusted for age and sex* } \\
\text { (model 1) }\end{array}$ & $\begin{array}{l}\text { Incidence rate ratios adjusted for } \\
\text { age, sex, and the factors in table } 1 \\
\text { and table } 2 \text { (model 2) }\end{array}$ \\
\hline \multicolumn{4}{|c|}{ Time since last discharge from psychiatric inpatient care } \\
\hline Currently admitted & $722 / 393$ & 71.89 (62.23 to 83.05$)$ & $53.74(46.38$ to 62.28$)$ \\
\hline Discharged within the past 8 days & $283 / 38$ & 310.65 (214.97 to 448.92$)$ & $271.56(186.51$ to 395.40$)$ \\
\hline Discharged within the past $8-30$ days & $349 / 98$ & $148.12(116.11$ to 188.94$)$ & 120.73 (94.04 to 154.98$)$ \\
\hline Discharged within the past $1-6$ months & $868 / 532$ & 66.81 (58.85 to 75.85$)$ & $50.00(43.88$ to 56.96$)$ \\
\hline Discharged within the past 7-12 months & $410 / 534$ & 30.48 (26.38 to 35.22$)$ & 22.03 (18.98 to 25.58$)$ \\
\hline Discharged more than a year ago & $1936 / 7502$ & 10.11 (9.47 to 10.79 ) & 7.29 (6.79 to 7.82$)$ \\
\hline Never admitted & $4443 / 171123$ & & 1 \\
\hline \multicolumn{4}{|l|}{ Psychiatric disorder at latest discharge } \\
\hline Depression & $359 / 427$ & $1.60(1.35$ to 1.91$)$ & $2.00(1.67$ to 2.39$)$ \\
\hline Schizophrenia & $488 / 716$ & 0.75 (0.65 to 0.87 ) & 0.58 (0.49 to 0.67$)$ \\
\hline Manic disorder & $128 / 201$ & 1.11 (0.85 to 1.44$)$ & $1.07(0.82$ to 1.40$)$ \\
\hline Alcohol misuse & $703 / 1521$ & $0.91(0.81$ to 1.02$)$ & $0.77(0.69$ to 0.87$)$ \\
\hline All other psychiatric disorders & $2890 / 6232$ & 1 & 1 \\
\hline \multicolumn{4}{|l|}{ Death among children } \\
\hline Child death by suicide & $17 / 90$ & $4.43(2.63$ to 7.45$)$ & 2.31 (1.23 to 4.34$)$ \\
\hline Child death by other cause & $114 / 1300$ & 2.24 (1.85 to 2.73 ) & $1.90(1.51$ to 2.40$)$ \\
\hline Child alive & $5303 / 127504$ & 1 & 1 \\
\hline \multicolumn{4}{|l|}{ Number of children } \\
\hline One child & $1762 / 35432$ & $0.66(0.62$ to 0.70$)$ & $0.92(0.85$ to 0.99$)$ \\
\hline Two children & $2418 / 61764$ & $0.49(0.46$ to 0.51$)$ & $0.88(0.82$ to 0.96$)$ \\
\hline Three or more children & $1254 / 31698$ & $0.47(0.44$ to 0.51$)$ & $0.80(0.73$ to 0.88$)$ \\
\hline No children & $3577 / 51326$ & 1 & 1 \\
\hline \multicolumn{4}{|l|}{ Income } \\
\hline Lowest income quartile & $4351 / 44316$ & $3.37(3.16$ to 3.59$)$ & $1.42(1.30$ to 1.55$)$ \\
\hline Second lowest income quartile & $1888 / 44771$ & 1.45 (1.35 to 1.55$)$ & 1.14 (1.04 to 1.24$)$ \\
\hline Second highest income quartile & $1429 / 45296$ & $1.08(1.00$ to 1.16$)$ & $1.03(0.94$ to 1.12$)$ \\
\hline Highest income quartile & $1343 / 45837$ & 1 & 1 \\
\hline \multicolumn{4}{|l|}{ Labour market affiliation in the previous year } \\
\hline Recipient of social benefits/disability pension & $2520 / 17786$ & 5.05 (4.78 to 5.33 ) & $1.30(1.20$ to 1.42$)$ \\
\hline Unemployed $81 \%-100 \%$ of the year & $393 / 5522$ & $1.69(1.56$ to 1.82$)$ & $1.32(1.21$ to 1.44$)$ \\
\hline Unemployed $21 \%-80 \%$ of the year & $1356 / 18219$ & 2.38 (2.23 to 2.54$)$ & $1.39(1.29$ to 1.51$)$ \\
\hline Unemployed $1 \%-20 \%$ of the year & $852 / 15922$ & 2.31 (2.07 to 2.57 ) & $1.31(1.15$ to 1.48$)$ \\
\hline Fully or self employed & $3890 / 122771$ & 1 & 1 \\
\hline \multicolumn{4}{|l|}{ Educational attainment } \\
\hline No information & $380 / 6665$ & $0.96(0.86$ to 1.07$)$ & 0.91 (0.80 to 1.03$)$ \\
\hline High school & $407 / 5536$ & 1.24 (1.11 to 1.38$)$ & 1.07 (0.94 to 1.22 ) \\
\hline Vocational training & $3034 / 69804$ & 0.73 (0.69 to 0.77$)$ & $1.02(0.96$ to 1.09$)$ \\
\hline Bachelor or other of similar duration & $1041 / 25127$ & $0.69(0.65$ to 0.75$)$ & 1.06 (0.97 to 1.15 ) \\
\hline University master, PhD & $388 / 9086$ & 0.71 (0.64 to 0.79 ) & $1.08(0.95$ to 1.23$)$ \\
\hline Primary school & $3761 / 64002$ & 1 & 1 \\
\hline
\end{tabular}


Table 3 Suicide in relation to partner's psychiatric admission, death by suicide, or other modes of death and marital status

\begin{tabular}{|c|c|c|c|c|}
\hline Risk factor and category & $\begin{array}{l}\text { Men } \\
\text { Number of cases/ } \\
\text { controls }\end{array}$ & $\begin{array}{l}\text { Adjusted incidence* rate } \\
\text { ratios (model 3) }\end{array}$ & $\begin{array}{l}\text { Women } \\
\text { Number of cases/ } \\
\text { controls }\end{array}$ & $\begin{array}{l}\text { Adjusted incidence* rate } \\
\text { ratios (model } 3 \text { ) }\end{array}$ \\
\hline \multicolumn{5}{|l|}{ Psychiatric admission among spouses and cohabitees } \\
\hline Partner 1: admission after 31 Dec two years before & $48 / 251$ & 3.86 (2.65 to 5.63$)$ & $25 / 88$ & 6.87 (3.62 to 13.04$)$ \\
\hline Partner 1: admission before 31 Dec two years before & 204/2771 & $1.27(1.07$ to 1.51$)$ & $105 / 1056$ & $1.22(0.91$ to 1.62$)$ \\
\hline Partner never admitted & $2719 / 84964$ & 1 & $1375 / 43080$ & 1 \\
\hline \multicolumn{5}{|c|}{$\begin{array}{l}\text { Partner's suicide and death since } 31 \text { Dec two years } \\
\text { earlier }\end{array}$} \\
\hline Partner death by suicide & $16 / 9$ & $46.20(18.34$ to 116.40$)$ & $12 / 25$ & 15.75 (6.64 to 37.38$)$ \\
\hline Partner death by other cause & $37 / 87$ & $10.14(6.51$ to 15.80$)$ & $17 / 79$ & $3.33(1.54$ to 7.20$)$ \\
\hline Partner alive at the matching date & $2918 / 87890$ & 1 & $1476 / 44120$ & 1 \\
\hline \multicolumn{5}{|l|}{ Death among children } \\
\hline Child death by suicide & $8 / 48$ & $2.06(0.84$ to 5.07$)$ & $9 / 42$ & $2.30(0.92$ to 5.73$)$ \\
\hline Child death by other cause & $67 / 779$ & 1.85 (1.38 to 2.47$)$ & $47 / 521$ & 2.07 (1.39 to 3.09$)$ \\
\hline Child alive & $3542 / 84748$ & 1 & $1761 / 42756$ & 1 \\
\hline \multicolumn{5}{|l|}{ Number of children } \\
\hline One child & $1163 / 24191$ & 0.99 (0.90 to 1.08$)$ & $599 / 11241$ & 0.75 (0.65 to 0.87$)$ \\
\hline Two children & $1593 / 40603$ & $1.00(0.91$ to 1.10$)$ & $825 / 21161$ & $0.68(0.59$ to 0.79$)$ \\
\hline Three or more children & $861 / 20781$ & $0.94(0.84$ to 1.05$)$ & $393 / 10917$ & $0.56(0.47$ to 0.67$)$ \\
\hline No children & $2527 / 37305$ & 1 & $1050 / 14021$ & \\
\hline \multicolumn{5}{|l|}{ Marital status on 31 Dec two years earlier } \\
\hline Widow/widower & $89 / 681$ & 2.98 (2.30 to 3.87$)$ & $119 / 1686$ & 1.56 (1.20 to 2.02$)$ \\
\hline Separated & $304 / 2923$ & 1.93 (1.67 to 2.23 ) & $182 / 1514$ & 1.97 (1.58 to 2.45$)$ \\
\hline Divorced & $775 / 6780$ & 1.75 (1.58 to 1.95$)$ & $540 / 4442$ & 1.68 (1.46 to 1.95$)$ \\
\hline Never married & $2005 / 24510$ & 1.48 (1.34 to 1.64$)$ & $521 / 5474$ & $1.36(1.14$ to 1.61$)$ \\
\hline Cohabitant and living with partner & $772 / 18275$ & 1.16 (1.05 to 1.28$)$ & $290 / 6177$ & $1.02(0.86$ to 1.22$)$ \\
\hline Married and living with spouse & $2199 / 69711$ & 1 & $1215 / 38047$ & 1 \\
\hline
\end{tabular}

*Adjusted for the age and the factors shown in table 2. Values are risk ratios (95\% confidence intervals).

suicide risk was increased in the unemployed and those outside the labour market, in those with lower income, but unrelated to educational attainment.

Table 3 shows the results from the gender stratified model (model 3). Although not statistically distinct by gender, the partner's recent psychiatric admission increased the suicide rate numerically more in women. Bereavement by suicide was more indicative of suicide in women $(\mathrm{W}=7.06, \mathrm{df}=1$, $\mathrm{p}=0.008)$ and men $(\mathrm{W}=8.42, \mathrm{df}=1,=0.004)$ than bereavement after other modes of death. The association with a partner's death by other causes was more pronounced in men (rate $=2.92, \mathrm{~W}=6.02, \mathrm{df}=1, \mathrm{p}=0.01)$, and although not statistically significant, the rate was considerably higher (about 3.05) in men whose partner committed suicide compared with their female counterparts. The suicide rate in widowers was significantly higher than the suicide rate in widows. The rates associated with losing a child differed little by gender and cause of death, and having children was only protective in mothers. While the interaction between own and partner's psychiatric admission was non-significant $(\mathrm{W}=1.89, \mathrm{df}=2, \mathrm{p}=0.39)$, the additional interaction effect of own psychiatric admission and partner's death (risk ratio $0.35 ; 95 \%$ confidence interval, 0.16 to 0.79 , number cases/ controls $=15 / 29$ ) and the additional interaction effect of partner's death and partner's admission $(0.31 ; 0.15$ to 0.66 , number cases/controls $=55 / 26$ ) did not further increase the suicide risk.

\section{DISCUSSION}

\section{Main results}

Suicide is more common in both husbands and wives whose marital partner has been admitted to a psychiatric hospital, especially if the first admission has been within the past two years, if their partner or child has died, especially if the partner died by suicide or the subject is male, if they are living alone whether they are separated, divorced, or never married. While the impact on the suicide risk of partner's admission with a psychiatric disorder did not differ by gender, being a parent is only protective against suicide in women.

\section{Partner's psychiatric admission}

In keeping with a previous study, ${ }^{13}$ the results further show that spousal psychiatric illness increases the suicide risk in both husbands and wives, which suggests that mental illness could have an impact on other family members beyond a social impact. ${ }^{33}$ The suicide risk increase associated with partner's recent admission is almost two times higher in women, but had the study, in contrast with fact, found a significant gender difference, then the association would more probably have been causal.

Although people tend to marry people with resembling traits, ${ }^{14}$ such as those associated with psychiatric illness, ${ }^{34}$ and while a study has suggested that patients with schizophrenia might find a marital partner during admission, ${ }^{35}$ and even if shared environmental factors may put partners at risk of the same diseases, ${ }^{36}$ the suicide risk is not further influenced by the concordance of psychiatric admission. However, this does not entirely rule out the possibility that generic factors are at play through assortative mating, as psychiatric illnesses cluster in families. ${ }^{37}$

\section{Partner's suicide and death}

Conjugal bereavement has an impact on the mortality among surviving spouses, ${ }^{38}$ and spousal suicide bereavement might increase the suicide risk more than bereavement after other modes of death. ${ }^{13}$ In this study, spousal loss by suicide increased the suicide risk more in both genders, than spousal loss after other modes of death. Furthermore, men experienced an approximately three times higher suicide risk increase than their female counterparts when their partner died by other causes, which is in keeping with studies on elderly widowers. ${ }^{18}{ }^{39}$ Although non-significant, the results could show that this is also true for men bereaved by suicide. Men might be less prone to seek help, choose more lethal methods, be more impulsively violent, inclined to substance misuse, ${ }^{40}$ and might be more likely to suffer from untreated or undertreated mental illnesses. ${ }^{1}$ Furthermore, the data might cover a few cases of dyadic deaths, ${ }^{41}$ where men more often are the perpetrators. ${ }^{42}$ 


\section{Key points}

- Husbands and wives whose marital partner has been admitted with a psychiatric disorder are at increased risk of suicide.

- Conjugal bereavement is particularly indicative of suicide in men.

- Spousal suicide is particularly indicative of suicide.

- Child bereavement is associated with parental suicide in both parents.

- Being a parent is protective against suicide in women.

- Being separated, divorced, never married, or being cohabitant induce a similar suicide risk in both sexes.

Nevertheless, these gender differences suggest that assortative mating is a less likely explanation for a suicidal behaviour, and therefore, that this result is more probably attributed to an environmental factor than to a genetic susceptibility.

\section{Interactions between psychiatric admission and spousal death}

Although highly associated with suicide, the death of a partner increased the suicide risk less in previously admitted patients. This might suggest that psychiatric inpatient treatment could prevent suicide, or that a behavioural trait associated with some disorders (for example, a violent behaviour ${ }^{43}$ ) is related to the death, or simply, that there is an upper limit to grief. Likewise, experiencing a partner dying did not increase the risk to the same extent when the partner had been admitted with a psychiatric disorder. Recognising suicidal behaviour as a concomitant of psychiatric illness may alleviate the strain caused by the death of the mentally ill partner. However, a reverse causal relation cannot be ruled out as a study has suggested that people with severe mental illness are at increased risk of homicide ${ }^{44}$ Nevertheless, effect modifications should be interpreted with caution when the main effect is very strong. Lastly, the analysis could not distinguish the rates associated with whether the partner had been admitted with depression, schizophrenia, alcohol misuse, mania, or other psychiatric disorders.

\section{Child bereavement and parenthood}

Losing a child has an impact on parents' mental wellbeing ${ }^{45}$ and increases their suicide risk. ${ }^{16}$ The unadjusted analysis suggests that suicide bereavement of a child is more indicative of parental suicide than bereavement by other causes, while the adjustment for parental psychiatric admission level out the difference. However, parental psychopathology could be an intermediate stage on the causal pathway, and not only a confounding factor. In keeping with earlier studies, ${ }^{16}$ the results suggest that being a parent is protective against suicide only in women. However, a suicidal behaviour might diminish the chance of becoming a parent.

\section{Policy implications}

The suicide, death, or psychiatric illness of a family member can have a huge impact on the wellbeing of other family members

\section{Marital status}

People who are living alone have a higher suicide risk, or similarly marriage could be protective against suicide..$^{40}$ This study further suggests that the highest risk increase is in widows/widowers followed by separated, divorced and never married people, and the results confirm that widowers have a higher risk than widows. In contrast with a previous paper published in this journal, ${ }^{22}$ the results show that divorced men and women experience almost the same risk increase. Two explanations seem possible: one is that Danish women are often integrated on the labour market, so that they have the same social support and do not suffer a much higher economic loss when divorced, as explained by Kposowa. ${ }^{22}$ Another possible explanation is that the results are based on updated information on marital status as suggested earlier, ${ }^{46}$ and furthermore, the test for non-proportionality ${ }^{46}$ with age suggests that the risk increase associated with divorce declines with age. However, it is important to remember that there are more than two male suicides per female suicide.

\section{Weaknesses of the study}

This study has a number of shortcomings. For instance, the findings depend on the availability of data: an illness episode, which did not lead to admission, or a suicide reported as an accident or an open verdict, or missing links to children who were not living with their parent in 1968, could lead to a misclassification bias. In some instances, the statistical power is rather limited especially when considering gender differences associated with partner or child bereavement. ${ }^{47}$ As in most observational studies, the effects presented here do not necessarily equal the desired causal effects. ${ }^{48} \mathrm{~A}$ marital breakdown or other unobserved events in period between 31 December two years ago and the matching date could have influenced the results. Although the highest suicide rates are to be found among the elderly population, ${ }^{49}$ this study includes only people aged 25 to 60 years, which is an age range where spousal death is rare, usually sudden, and unanticipated.

In conclusion, the suicide risk is increased in people, whose partner has been admitted with a psychiatric disorder, whose child or partner has died, especially if the partner has died by suicide or if the subject is male, whereas having children seems only to protect against suicide in women but not in men. Despite the very high rates and because of the rarity of these stressful life events and suicide, targeting prevention efforts at families where such an event has occurred could probably prevent few suicides. On the other hand, few, if any strategies, for preventing suicide have been shown to reduce suicide. ${ }^{50} 51$

Funding: the study was financially supported by the Stanley Medical Research Institute. The National Centre for Register-based Research is funded by the Danish National Research Foundation.

Competing interest: none declared.

\section{REFERENCES}

1 Agerbo E, Nordentoft M, Mortensen PB. Familial, psychiatric, and socioeconomic risk factors for suicide in young people: nested case-control study. BMJ 2002;325:74-7.

2 Qin P, Agerbo E, Mortensen PB. Suicide risk in relation to family history of completed suicide and psychiatric disorders: a nested case-control study based on longitudinal registers. Lancet 2002;360:1126-30.

3 Runeson B, Asberg M. Family history of suicide among suicide victims. Am J Psychiatry 2003;160:1525-6.

4 Mann JJ. The neurobiology of suicide. Nat Med 1998;4:25-30.

5 Schulsinger F, Kety SS, Rosenthal D, et al. A family study of suicide. In: Schou M, Strömgren $E$, eds. Origin, prevention and treatment of affective disorder. London: Academic Press, 1979:279-87.

6 Roy A, Segal NL, Centerwall BS, et al. Suicide in twins. Arch Gen Psychiatry 1991;48:29-32.

7 Gould MS, Fisher P, Parides M, et al. Psychosocial risk factors of child and adolescent completed suicide. Arch Gen Psychiatry 1996;53:1155-62. 
8 Faraeone SV, Tsuang D, Tsuang MT. Methods in psychiatric genetics. In: Tsuang MT, Tohen M, eds. Textbook in psychiatric epidemiology.2nd ed. New York: Wiley, 2003:65-130.

9 Roy A, Nielsen D, Rylander G, et al. Genetics of suicide in depression. J Clin Psychiatry 1999;60(suppl 2):12-7, 18-20, 113-16.

10 Mann JJ. A current perspective of suicide and attempted suicide. Ann Intern Med 2002; 136:302-11.

11 Arango V, Huang YY, Underwood MD, et al. Genetics of the serotonergic system in suicidal behavior. J Psychiatr Res 2003;37:375-86.

12 Kamali M, Oquendo MA, Mann JJ. Understanding the neurobiology of suicidal behavior. Depress Anxiety 2001;14:164-76.

13 Agerbo E. Risk of suicide and spouse's psychiatric illness or suicide: nested case-control study. BMJ 2003;327:1025-6.

14 Joung IM, van de Mheen HD, Stronks K, et al. A longitudinal study of health selection in marital transitions. Soc Sci Med 1998;46:425-35.

15 Schaefer C, Quesenberry CP Jr, Wi S. Mortality following conjugal bereavement and the effects of a shared environment. Am J Epidemiol 1995; 141:1142-52.

16 Qin P, Mortensen PB. The impact of parental status on the risk of completed suicide. Arch Gen Psychiatry 2003;60:797-802.

17 Martikainen P, Valkonen T. Mortality after death of spouse in relation to duration of bereavement in Finland. J Epidemiol Community Health 1996:50:264-8.

18 Erlangsen $A$, Jeune $B$, Bille-Brahe $U$, et al. Loss of partner and suicide risks among oldest old: a population-based register study. Age Ageing 2004;33:378-83.

19 Siegel MJ, Bradley EH, Gallo WT, et al. The effect of spousal mental and physical health on husbands' and wives' depressive symptoms, among older adults: longitudinal evidence from the health and retirement survey. J Aging Health 2004; 16:398-425.

20 Clark SE, Goldney RD. The impact of suicide on relatives and friends. In: Hawton K, van Heeringen K, eds. The international handbook of suicide and attempted suicide. New York: Wiley, 2000:467-84.

21 Mortensen PB, Agerbo E, Erikson T, et al. Psychiatric illness and risk factors for suicide in Denmark. Lancet 2000;355:9-12.

22 Kposowa AJ. Marital status and suicide in the national longitudinal mortality study. J Epidemiol Community Health 2000;54:254-61.

23 Blakely TA, Collings SC, Atkinson J. Unemployment and suicide. Evidence for a causal association? J Epidemiol Community Health 2003;57:594-600.

24 Qin P, Agerbo E, Mortensen PB. Suicide risk in relation to socioeconomic, demographic, psychiatric, and familial factors: a national register-based study of all suicides in Denmark, 1981-1997. Am J Psychiatry 2003;160:765-72.

25 Malig C. The civil registration system in Denmark. International Institute for Vital Registration and Statistics [IIVRS]. Bethesda, MD, 1996:1-6.

26 Sundhedsstyrelsen (The Danish National Board of Health). Dødsaarsagerne 1990 (Cause of Death in Denmark 1990). Copenhagen: Sundhedsstyrelsen 1992.

27 World Health Organisation. Manual of the International Classification of Diseases (ICD-8). Geneva: WHO, 1967.

28 World Health Organisation. The ICD-10 Classification of Mental and Behavioural Disorders. Geneva: WHO, 1992.

29 Munk-Jorgensen P, Mortensen PB. The Danish Psychiatric Central Register. Dan Med Bull 1997;44:82-4.
30 Danmarks Statistik (Statistics Denmark). IDA - en integreret database for arbejdsmarkedsforskning (The Integrated Database for Longitudinal Labour Market Research). Copenhagen: Statistics Denmark Press, 1991.

31 Borgan O, Langholz B. Nonparametric estimation of relative mortality from nested case-control studies. Biometrics 1993;49:593-602.

32 Centrale Personregister. The Civil Registration System in Denmark. Chapter 2. Historical background, 2003. http://www.cpr.dk.

33 Fadden G, Bebbington P, Kuipers L. The burden of care: the impact of functional psychiatric illness on the patient's family. Br J Psychiatry 1987; 150:285-92

34 Maes HH, Neale MC, Kendler KS, et al. Assortative mating for major psychiatric diagnoses in two population-based samples. Psychol Med 1998:28:1389-401.

35 Agerbo E, Byrne, Eaton WW, et al. Marital and labor market status in the long run in schizophrenia. Arch Gen Psychiatry 2004;61:28-33.

36 Hippisley-Cox J, Coupland C, Pringle M, et al. Married couples' risk of same disease: cross sectional study. BMJ 2002;325:636.

37 Kendler KS, Davis CG, Kessler RC. The familial aggregation of common psychiatric and substance use disorders in the national comorbidity survey: a family history study. Br J Psychiatry 1997;170:541-8

38 Lichtenstein P, Gatz M, Berg S. A twin study of mortality after spousal bereavement. Psychol Med 1998;28:635-43.

39 Li G. The interaction effect of bereavement and sex on the risk of suicide in the elderly: an historical cohort study. Soc Sci Med 1995;40:825-8.

40 Cantor $\mathrm{CH}$. Suicide in the western world. In: Hawton K, van Heeringen K, eds. The international handbook of suicide and attempted suicide. New York: Wiley, 2000:9-28.

41 Milroy CM. The epidemiology of homicide-suicide (dyadic death). Forensic Sci Int 1995;71:117-22.

42 Marzuk PM, Tardiff K, Hirsch CS. The epidemiology of murder-suicide. JAMA 1992;267:3179-83.

43 Nock KN, Marzuk PM. Suicide and violence. In: Hawton K, van Heeringen K, eds. The international handbook of suicide and attempted suicide. New York: Wiley, 2000:437-56.

44 Hiroeh U, Appleby L, Mortensen PB, et al. Death by homicide, suicide, and other unnatural causes in people with mental illness: a population-based study. Lancet 2001;358:2110-12.

45 Brent DA, Moritz G, Bridge J, et al. The impact of adolescent suicide on siblings and parents: a longitudinal follow-up. Suicide Life Threat Behav 1996;26:253-9.

46 Cheung YB, Yip PS. Marital status and suicide: some common methodological problems. J Epidemiol Community Health 2000;54:878.

47 Miettinen OS. Individual matching with multiple controls in the case of all-ornone responses. Biometrics 1969;25:339-55.

48 Hernan MA. A definition of causal effect for epidemiological research. $J$ Epidemiol Community Health 2004;58:265-71.

49 Erlangsen A, Bille-Brahe U, Jeune B. Differences in suicide between the old and the oldest old. J Gerontol B Psychol Sci Soc Sci 2003;58:314-22.

50 Gunnell D, Frankel S. Prevention of suicide: aspirations and evidence. BMJ 1994;308:1227-33.

51 Lewis G, Hawton K, Jones P. Strategies for preventing suicide. Br J Psychiatry 1997:171:351-4. 